\title{
Microhardness of Esthetic Restorative Materials at Different Depths
}

\author{
Regina Guenka Palma-Dibb ${ }^{\mathrm{a} *}$, Alessandra Elias Palma ${ }^{\mathrm{a}}$,Edmir Matson ${ }^{\mathrm{b}}$, \\ Michelle Alexandra Chinelatti, Renata Pereira Ramos ${ }^{\mathrm{a}}$ \\ ${ }^{\mathrm{a}}$ Department of Restorative Dentistry, \\ Ribeirão Preto School of Dentistry, University of São Paulo, Ribeirão Preto - SP, Brazil \\ ${ }^{\mathrm{b}}$ Department of Restorative Dentistry, Endodontics and Dental Materials, \\ School of Dentistry, University of São Paulo, São Paulo - SP, Brazil
}

Received: April 26, 2002; Revised: October 8, 2002

\begin{abstract}
The aim of this study was to analyze the microhardness of two resin-modified glass ionomer cements (Vitremer; Fuji II LC); two polyacid-modified composite resins (Freedom; F2000) and a hybrid composite resin (Prodigy), at different depths from the upper surface. Six hemi-cylinders ( $3 \mathrm{~mm}$ height; $3 \mathrm{~mm}$ radius) per tested material were obtained. Vickers Hardness was determined using a micro-indentation tester. For each hemi-cylinder, three indentations were taken at one of the following depths: 0.4, 1.0, 2.0 and $2.6 \mathrm{~mm}$. For each material, microhardness average was calculated. Statistical analysis was performed using two-way ANOVA and Tukey test Fuji II LC and Vitremer showed no statistically significant difference among hardness means recorded at the four analyzed depths. The hybrid and the polyacid-modified composite resins showed significant decrease microhardness with increasing depth. It may be concluded that for the RMGIC, microhardness was not affected at depths up to $2.6 \mathrm{~mm}$. On the other hand, both hybrid and PMCRs should de better placed in increments not thicker than $2 \mathrm{~mm}$ to achieve optimal hardness throughout the restoration.
\end{abstract}

Keywords: composite resin, glass ionomer cement, compomer, microhardness

\section{Introduction}

The conventional glass-ionomer cements (GIC) were first described in the 1970's as materials consisting of a base, usually an ion-leachable glass powder, which is combined with a polyacrylic acid or its copolymers. Several features contributed to the wide acceptance of GIC in dental practice, including biocompatibility ${ }^{1,2}$, good adhesion to tooth substrates $^{2}$, ability to take up and release fluoride ${ }^{1-4}$, minimal shrinkage on setting ${ }^{2}$ and a coefficient of thermal expansion similar to that of tooth structure ${ }^{5}$. However, the problems associated to conventional glass-ionomer cements include early low mechanical strengths, limited aesthetics resulting from moisture sensitivity and susceptibility to fracture and dehydration, especially during the initial stages of setting reaction ${ }^{6-8}$. These characteristics may lead to de- creased physical properties, thereby limiting the applicability ${ }^{9}$ of glass ionomer cements to certain clinical situations.

In view of these shortcomings, attention was directed at improving properties and handling characteristics of glassionomer cements, and a further evolution combined lightcured composite resin and GIC technology. The term "resinmodified glass-ionomer cements" (RMGIC) refers to materials formed by adding a small amount of polymerizable resin components, usually 2-hydroxyethyl methacrylate (HEMA) or bisphenol glycidyl methacrylate (Bis-GMA), to the GIC formulation, with the main purpose of enhancing the early properties of the material. Upon mixing, these materials undergo an acid-base reaction in addition to visible-light activation. The ongoing acid-base reaction and dark cure component of free radical resin polymerization 
are responsible for the post-hardening of these cements ${ }^{10-12}$.

Recently, another category of light-cured restorative materials, which contain GIC components and release fluoride, was introduced to market. These materials, termed "polyacid-modified composite resins" (PMCR) or "compomers" may not be classified as conventional glassionomer cements, as they are presented as one-component resin-based products and do not have an acid-base reaction which occurs without photoactivation ${ }^{13}$ and diffusion of water, and, when set, do not exhibit the typical properties of true GIC.

Compared to conventional GIC, the hybrid glass ionomer cements and compomers are claimed to possess improved physical properties ${ }^{4,7}$, decreased sensitivity to water loss and absorption, enhanced esthetics and longer working-time ${ }^{11}$. Nevertheless, it has also been reported that these materials may undergo alterations, depending on light-curing process, that could affect the extent of polymerization at different depths.

Since the introduction of light-cured restorative materials, there has been concern about the depth of appropriate cure throughout the restoration. Recent studies have indicated that the resin materials themselves or the light sources used to activate curing process may not provide optimal polymerization in the deepest areas of the restoration ${ }^{11}$. The restoration may be mechanically compromised by the incomplete cure of the mass of the restorative material at the bottom surface ${ }^{9,11}$. Moreover, unreacted components may leach from the restoration, increasing the potential for an adverse biocompatibility reaction ${ }^{11}$.

The polymerization depth of visible light-activated materials is directly related to the thickness of the material and is also influenced by light intensity ${ }^{14,15}$. In addition, other factors also affect this property such as the measurement method, matrix/mould composition and dimensions of light source and its distance to the tested surface ${ }^{10,16,17}$. Moreover, it has been widely reported that the top surface presents higher hardness than the bottom surface of restorations ${ }^{14,18}$.
However, the different types of restorative materials currently available may yield different performances with respect to the depth of cure. Therefore, the purpose of this investigation was to assess the microhardness of two polyacid-modified composite resins, two resin-modified glass ionomer cements, and a hybrid composite resin, at different depths from the top surface.

\section{Material and Methods}

The tested materials with their compositions, specifications and manufacturers are listed on Table 1.

Thirty specimens were prepared using a black polyurethane cylindrical split mould with $3 \mathrm{~mm}$ in height and $6 \mathrm{~mm}$ in diameter (Fig. 1a). The cylindrical mould was placed in a metallic clamping apparatus (Fig. 1b and Fig. 1c) and bisected by a stainless steel sheet, thus forming a separated cavity (Fig. 1d). The goal of using the stainless steel sheet was to obtain a smooth, flattened surface on which Vickers hardness was assessed. The cavity formed was then slightly filled in a single increment with the following materials: two resin-modified glass ionomer cements Vitremer (3M Dental Products, St Paul, MN 55144) and Fuji II LC (GC Corporation, Tokyo, Japan); two polyacid-modified composite resins Freedom (Southern Dental Industries, Bayswater, Victoria, Australia) and F2000 (3M Dental Products, St Paul, MN 55144); and a hybrid composite resin Prodigy (Kerr Corporation, Orange, CA 92667). The RMGIC components (powder and liquid) were disposed, mixed according to the manufacturers' instructions and injected into the matrix cavity with a Centrix injector (Cavifil Injector - Vivadent, Schaan, Liechtenstein) to prevent bubbles, voids and air entrapment. After insertion, the increment was covered and gently pressed by a clear polyester matrix strip and light-cured for $60 \mathrm{~s}$ using a visible lightcuring unit with a $450 \mathrm{~mW} / \mathrm{cm}^{2}$ output (XL 3000, 3M Dental Products, St Paul, MN 55144).

The split mould was removed from the clamping device thereby providing a hemi-cylinder with the same dimen-

Table 1. Tested materials

\begin{tabular}{ccccc}
\hline Material (Shade) & Manufacturer & Batch number & Type of Material & Powder/Liquid Ratio (g) \\
\hline Vitremer (A3) & 3 M Dental Products & $\begin{array}{c}\text { Powder-19970717 } \\
\text { Liquid-199770709 }\end{array}$ & $\begin{array}{c}\text { Resin-modified } \\
\text { glass ionomer cement }\end{array}$ & $2.5 / 1$ \\
\hline Fuji II LC (A3) & GC Corporation & $\begin{array}{c}\text { Powder-070181 } \\
\text { Liquid-260181 }\end{array}$ & $\begin{array}{c}\text { Resin-modified } \\
\text { glass ionomer }\end{array}$ & 3.2/1 \\
\hline F2000 (A3) & 3M Dental Products & 23038 & $\begin{array}{c}\text { Polyacid-modified } \\
\text { composite resin }\end{array}$ & - \\
\hline Freedom (A3) & Southern Dental Industries & 2256 & $\begin{array}{c}\text { Polyacid-modified } \\
\text { composite resin }\end{array}$ & - \\
\hline Prodigy (A3) & Kerr Corporation & 710328 & Hybrid composite resin & - \\
\hline
\end{tabular}



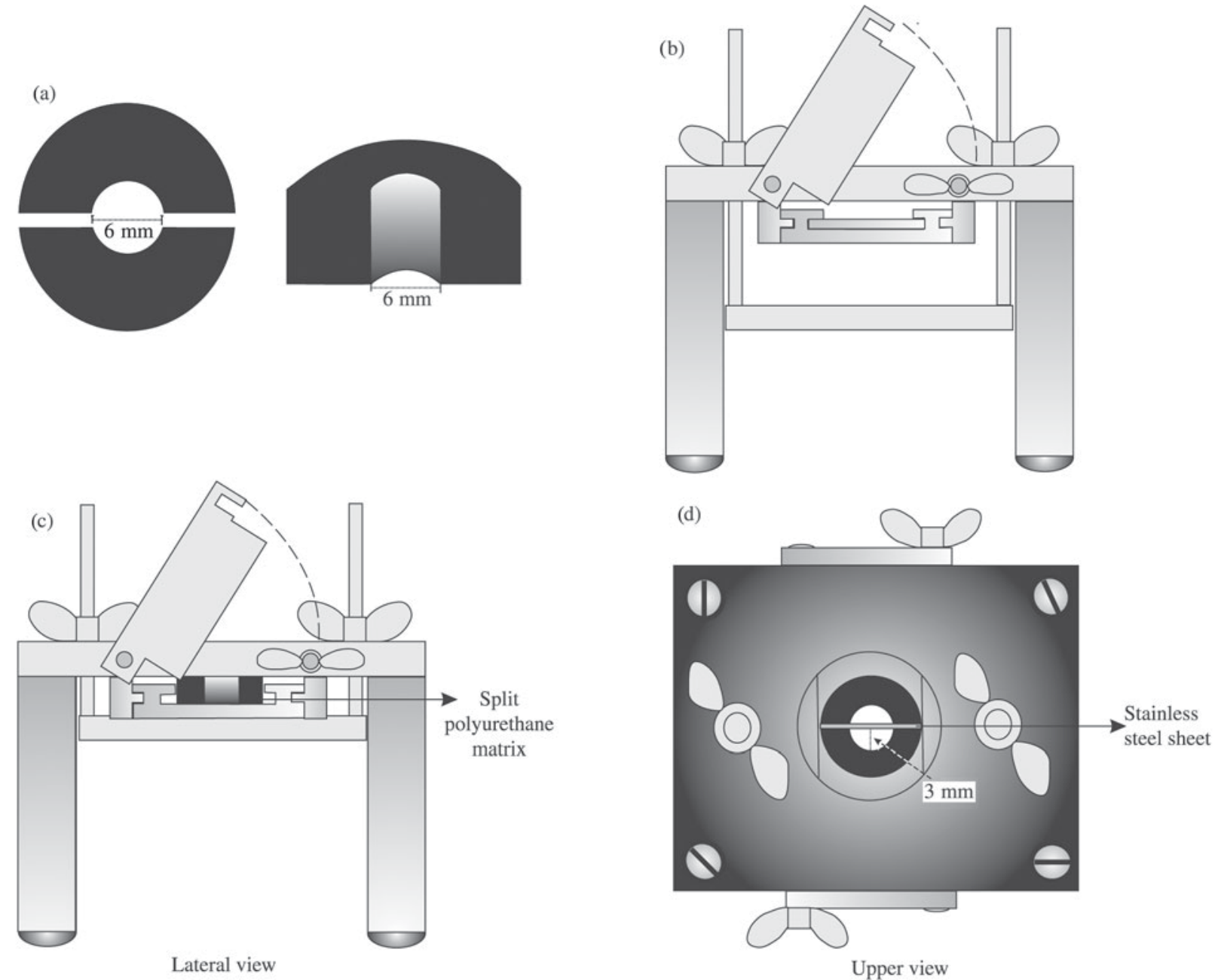

(e)

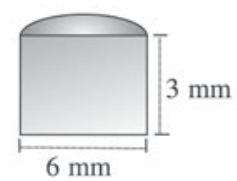

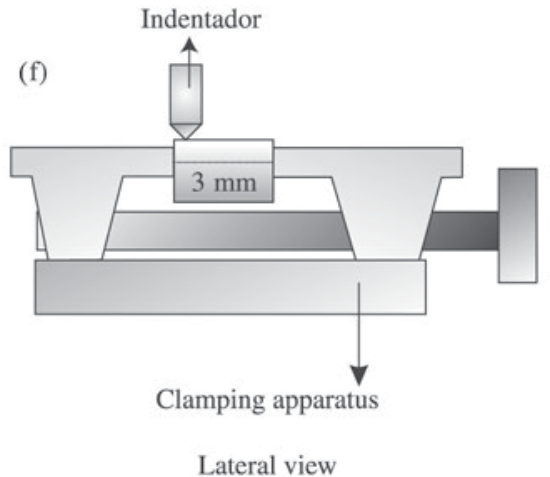

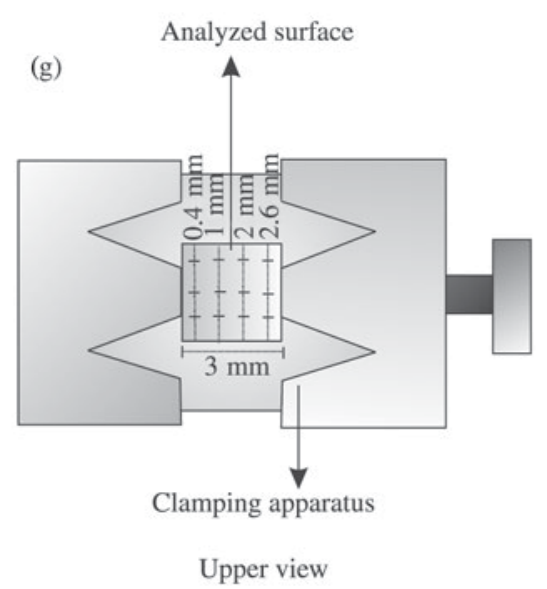

Figure 1. Schematic representation of specimen preparation and microhardness indentations. (a) Split polyurethane matrix; (b) Metallic clamping device; (c) Split matrix positioned in the clamping device; (d) Matrix bisected by a stainless steel sheet; (e) Hemi-cylinder; (f) Hemi-cylinder fixed in a clamping apparatus and positioned in the hardness micro-indentation tester; (g) Hemi-cylinder after microhardness indentations. 
sions of the bisected cavity $(3 \mathrm{~mm}$ in height and $6 \mathrm{~mm}$ in diameter) (Fig. 1e). Six specimens per material were obtained. The hemi-cylinders were stored for $24 \mathrm{~h}$ inside a lightproof container with distilled water at $37{ }^{\circ} \mathrm{C}$. Afterwards, Vickers hardness was measured on the surface in contact with the stainless steel sheet using a micro-indentation tester (Shimadzu Micro Hardness Testers HMV-2, Shimadzu Corporation, Kyoto, Japan) with a $100 \mathrm{~g}$ load applied for $45 \mathrm{~s}$. The specimens were individually fixed in a clamping apparatus and positioned in such a way that the test surface was kept perpendicular to the indentator (Fig. 1f). Measurements were accomplished at depths of $0.4 \mathrm{~mm}, 1.0 \mathrm{~mm}, 2.0 \mathrm{~mm}$ and $2.6 \mathrm{~mm}$ from the upper surface of specimen. In each sample, three indentations equally spaced over a circle and not closer than $1 \mathrm{~mm}$ to the adjacent indentations or the margin of the specimen were taken at the all predetermined depths (Fig. 1g) and the averaged was calculated. Then, for each tested material, a microhardness mean value was determined at the specified depths of cure.

Statistical analysis was performed using two-way ANOVA using a factorial design with material and depth as independent variables. Means were compared to Tukey interval calculated at the 0.05 significance level. A software* was used to tabulate and analyze data.

\section{Results}

Microhardness means recorded at the different depths of cure and standard deviation are shown in Table 2. Statistical analysis of the data revealed significant difference ( $\mathrm{p}<0.05)$ among the experimental groups. Comparing the materials, regardless of the depth of cure, Fuji II LC (50.37 Hv) and Prodigy (47.11 Hv) showed statistical similarity and yielded the highest means. On the other hand, Freedom $(30,32 \mathrm{Hv})$ presented the lowest overall microhardness mean.

With respect to the depth of cure, regardless of the tested material, it was noticed that the $0.4 \mathrm{~mm}$ was statistically different $(\mathrm{p}<0.05)$ to the other depths. At $2.6 \mathrm{~mm}$, the lowest average was observed.
Analyzing the interaction of both variables, it was observed that for both resin-modified glass ionomer cements no statistically significant difference was found among microhardness means recorded at all the analyzed depths of cure (Table 2). The polyacid-modified and the hybrid composite resins showed a significant decrease in microhardness with the increase of depth of cure, mainly after $2.0 \mathrm{~mm}$ depth. Among these materials, the lowest mean was found for Freedom at $2.6 \mathrm{~mm}$ depth.

\section{Discussion}

The analysis of data demonstrated that for both RMGIC (Vitremer and Fuji II LC), statistically similar microhardness means were observed at all the analyzed depths, possibly due to the acid-base reaction and chemical-free radical polymerization that continue after the removal of the lightsource and therefore ensure a complete hardening of the material. Nevertheless, statistically significant difference $(\mathrm{p}<0.05)$ was found when the overall results of the RMGIC were compared one to another, regardless of the depth of cure: Vitremer $(35.09 \mathrm{Hv})$ and Fuji II LC (50.37 Hv). A possible explanation for such performances would be ascribed to differences in formulation, since these materials can be assigned to two different subgroups ${ }^{19}$ : those, such as Fuji II LC, in which polymerizable monomers like HEMA are merely blended with a polyalkenoic acid liquid, and those, such as Vitremer, in which in addition to the simple mixture of HEMA with a polyalkenoic acid, the latter itself

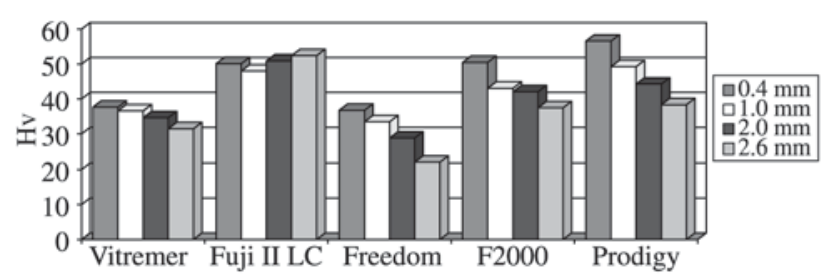

Figure 2. Distribution of Vivkers hardness $(\mathrm{Hv})$ at the analyzed depths of cure.

Table 2. Means (Hv) and standard deviation of the experimental groups

\begin{tabular}{|c|c|c|c|c|c|}
\hline \multirow[t]{2}{*}{ Depth $(\mathrm{mm})$} & \multicolumn{5}{|c|}{ Restorative Materials } \\
\hline & Vitremer & Fuji II LC & Freedom & F2000 & Prodigy \\
\hline 0.4 & 37.66 (4.14) & $50.13(8.10)$ & $36.78(3.07) \mid$ & $50.47(3.68) \mid$ & 56.57 (7.09)| \\
\hline 1.0 & 36.59 (3.17) & $48.02(6.36)$ & 33.48 (4.09) & $43.07(8.17)$ & $49.23(6.56) \mid$ \\
\hline 2.0 & $34.62(2.56)$ & $50.90(4.92)$ & $28.84(6.52) \mid$ & $42.06(4.41) \mid$ & 44.27 (7.10)| \\
\hline 2.6 & $31.48(3.63) \mid$ & $52.41(8.29) \mid$ & $22.15(4.52) \mid$ & 37.49 (6.70)| & 38.37 (2.41)| \\
\hline $\bar{X}$ & 35,09 & 50,37 & 30,32 & 43,28 & 47,11 \\
\hline
\end{tabular}

Means connected by the same bar showed statistical similarity

Tukey critical value: 3.84

*GMC Statistical Software- v.2002 - Prof. Geraldo Maia Campos

"Estatística Prática para Docentes e Pós-Graduandos"

(Online version) - http://www.forp.usp.br/restauradora/gmc/gmc.html 
is also modified by the attachment of polymerizable methacrylate side groups ${ }^{19}$. Furthermore, the great diversity in particle-size distribution among the hybrid materials indicates that the manufacturers may fill the matrix in different ways. Some of them add a great amount of small particles to large particles, while another manufacturers opt for many large particles added to a smaller amount of small particles, as in Fuji II LC. For Vitremer, the amount of small and large particles is more equally distributed. Although the optimal packing of filler particles in hybrid restorative materials does not yet appear to have been established, the differences between the materials may have influenced the better performance of Fuji II LC over Vitremer.

Studies ${ }^{9,20}$ have indicated that glass-ionomer cements hardness usually increases in a humid environment and with time. When the storage media is either water or saliva, the surface hardness is not affected or is slightly decreased after initial setting. However, when the materials are contaminated with saliva before set, it may result in significant alteration of microhardness. In the conducted research, specimens were stored in distilled water for $24 \mathrm{~h}$ previously to microhardness indentation test and the analysis of the results disclosed that both RMGICs showed statistically similar hardness at almost all tested depths. Conversely, it has been reported that the storage of polyacid-modified composite resins in either aqueous solution or saliva $(58,3 \mathrm{Hv})$ led to significant decrease in microhardness when the results were compared to those recorded after dry storage $(95,1 \mathrm{Hv})$, thus indicating a significant surface degradation ${ }^{18,21}$.

The findings of the reported study disclosed that microhardness means recorded for the resin-modified glass ionomer cements were comparable to those registered for the hybrid composite resin and considerably higher than those recorded for the polyacid-modified composite resins. Likewise, an earlier investigation ${ }^{10}$ also compared different esthetic restorative materials and found that the tested RMGICs yielded microhardness means equivalent to those of composite resins and higher than conventional glass ionomer cements.

In general, the polyacid modified and the hybrid composite resins showed significant decrease in microhardness with the increase of the depth of cure, and this drop was particularly evident at depths higher than $2 \mathrm{~mm}$ from the light source, what would compromise their clinical performance. A possible explanation for such performance would be the fact that the polymerization of these materials rely exclusively upon light activation and thus require maximum proximity to the light source ${ }^{22}$. In addition to this, lightcured composite resins require optimal light intensity, sufficient irradiation time and a maximal thickness to allow the appropriate penetration of light throughout the restorative material placed in cavity preparation ${ }^{23,24}$.

While the tested composite resins presented higher microhardness at regions closer to the upper surface of the specimens, the resin-modified glass ionomer cements, especially Fuji II LC, did not show a significant decrease in microhardness with the increase of depth of cure.

Further investigation is certainly required to establish the basis to yield an optimized and rational assessment of microhardness as well as to assess the influence of storage time on the properties of light-cured restorative materials, especially the resin-modified glass-ionomer cements.

\section{Conclusions}

Based on the findings of the reported research, and within the limitations of an in vitro study, it may be concluded that for the resin-modified glass ionomer cements, microhardness was not affected at depths up to $2.6 \mathrm{~mm}$, what leads to the assumption that these materials may be successfully placed into cavity preparations and further lightcured in a single increment. On the other hand, hybrid and polyacid-modified composite resins should be better placed in increments not thicker than $2 \mathrm{~mm}$ to achieve optimized hardness throughout the restoration.

\section{References}

1. Wilson, A.D.; Kent, B.E. British Dental Journal, v. 132, p. 133, 1972.

2. Navarro, M.F. de L.; Pascotto, R. Glass ionomer cement. São Paulo, Artes Médicas, p. 179, 1997.

3. Barnes, D.M.; Blank, L.W. Journal American Dental Association, v. 126, p. 1245, 1995.

4. Sidhu, S.K.; Watson, T.F. American Journal of Dentistry, v. 8, p. 59, 1995.

5. Abdalla, A.I.; Alhadainy, H.A.; Garcia-Godoy, F. American Journal of Dentistry, v. 10, p. 19, 1997.

6. Goldman, M. J. Biomedical Materials Science, v. 10, p. 771, 1985 .

7. Kerby, R.E.; Knobloch, L.; Thakur, A. Operative Dentistry, v. 22, p. 79, 1997.

8. Mount, G.J.; Makinson, O.F. Operative Dentistry, v. 7, p. 134, 1982.

9. Dupuis, V.; Moya, F.; Payan, J.; Bartala, M. Biomaterials, v. 17, p. 71, 1996.

10. Kanchanavasita, W.; Anstice, H.M.; Pearson, G.J. Journal of Dentistry, v. 26, p. 707, 1998.

11. Atmadja, G.; Bryant, R.W. Australian Dental Journal, v. 35, n. 3, p. 213, 1990.

12. Tyas, M.J. Operative Dentistry, v. 23, p. 77, 1998.

13. McLean, J.W.; Nicholson, J.W.; Wilson, A.D. Quintessence International, v. 25, p. 587, 1994.

14. Correr Sobrinho, L.; De Goes, M.F.; Consani, S.; Sinhoreti, M.A.C. Journal of Materials Science: Materials in Medicine, v. 11, p. 361, 1994.

15. DeWald, J.P.; Ferracane, J.L. Journal of Dental Research, 
v. 66, p. 727, 1987.

16. Yearn, J.A. International Dental Journal, v. 35, p. 218 , 1985.

17. Mitra, S.B. Proceedings of the $2^{\text {nd }}$ International Symposium on Glass ionomers. Philadelphia, PA: International Symposia in Dentistry, 1992.

18. Geurtsen, W.; Leyhausen, G.; Garcia-Godoy, F. Dental Materials, v. 15, p. 196, 1999.

19. Gladys, S.; Van Meerbeek, B.; Braem, M.; Lambrechts, P.; Vanherle, G. Journal of Dental Research, v. 76, n. 4, p. 883, 1997.
20. De Moor, R.J.G.; Veerbeeck, R.M.H. Biomaterials, v. 19, p. 2269, 1998.

21. Milleding, P; Ahlgren, F.; Wennerberg, A.; Örtengren, $\mathrm{U}$; Karlsson, S. International Journal of Prosthodontics, v. 1, p. 21, 1998.

22. Abate, P.F.; Polack, M.A.; Macchi, R.L. Quintessence International, v. 28, n. 5, p. 345, 1997.

23. Brosh, T.; Baharav, H.; Gross, O.; Laufer, B.Z. Journal of Prosthetic Dentistry, v. 77, p. 573, 1997.

24. Pilo, R.; Oelgiesser, D.; Cardash, H.S. Journal of Dentistry, v. 27, p. 235, 1999. 